\title{
Kinezyo Bantlama Uygulamasının Genç Kadınlarda Menstrüel Semptomlar Üzerine Etkisi
}

\author{
Eda Akbaş@ $[$, Emin Ulaş Erdem (1)
}

Bülent Ecevit Üniversitesi, Sağlık Bilimleri Fakültesi, Fizyoterapi ve Rehabilitasyon, Zonguldak, Türkiye

Eda Akbaş, Dr. Fzt. Emin Ulaş Erdem, Dr. Fzt.
İletişim:

Dr. Fzt. Eda Akbaş

Bülent Ecevit Üniversitesi Sağlık Bilimleri Fakültesi, Fizyoterapi ve Rehabilitasyon, Zonguldak, Türkiye

Tel: +903722613368

E-Posta: akbas.pt@gmail.com
Gönderilme Tarihi : 30 0cak 2018

Revizyon Tarihi : 27 Şubat 2018

Kabul Tarihi

: 21 Mart 2018
ÖZET

Amaç: Bu çalışma, kinezyo bantlama (KB) uygulamasının genç kadınlarda, menstrüel semptomlar üzerine etkinliğini araştırmak amacıyla planlanmıştır.

Hastalar ve Yöntem: 18-22 yaşları arasında 28 kadın rastgele yöntemle kinezyo bantlama (KBG, $n=14$ ) ve kontrol grubuna (KG, $n=14$ ) ayrıldı. Menstrüel semptomların şiddeti Vizüel Analog Skala (VAS) ile çalışmaya katıldıktan sonraki ilk menstrüasyon fazı ve bunu takip eden menstrüasyon fazı dahil olmak üzere toplamda iki defa, kanamanın başlangııında, 2, 6, 12, 24, 48 ve 72 saat sonra, değerlendirildi. KBG grubuna ikinci menstrüel fazda kanamanın başlamasından sonra KB uygulanırken, KG' ye herhangi bir müdahale yapılmadı.

Bulgular: KBG' de, 2. saatte baş ağrısı ve mide bulantısı; 6. saatte karın ağrısı ve baş dönmesi; 12. saatte karın ağrısı, bel ağrısı ve yorgunluk; 24 saatte karın ağrısı, bel ağrısı, uyluk ağrısı, bulantı, baş dönmesi ve yorgunluk; 72. saatte karın ağrısı, bel ağrısı ve yorgunluk, önceki menstrüasyon evresine göre anlamlı derecede düşük bulun$d u(p<0,05)$. KG' de, 6 . saatte baş dönmesi; 12 . saatte uyluk ağrısı ve yorgunluk bir önceki menstrüasyon evresine göre anlamlı derecede düşük bulundu $(\mathrm{p}<0,05)$.

Sonuç: Genç kadınlar menstrüel semptomları azaltmak için alternatif, basit, güvenilir ve etkili bir yöntem olan kinezyo bantlama uygulamasından yararlanabilirler.

Anahtar sözcükler: Kinezyo bantlama, menstrüel ağrı, menstürel semptomlar, VAS

\section{THE EFFECT OF KINESIOTAPE APPLICATION ON MENSTRUAL SYMPTOMS IN YOUNG WOMEN}

\section{ABSTRACT}

Objectives: This study was planned to investigate the efficacy of kinesio Tape (KT) application for menstrual symptoms in young women.

Patients and Methods: Twenty-eight women aged between 18-22 years were randomly assigned to Kinesio Tape group (KTG, $n=14$ ) and control group ( $(G, n=14)$. The intensity of menstrual symptoms were assessed with Visual Analogue Scale (VAS) twice in total, including the first menstruation phase and the subsequent menstruation phase immediately after participating in the study, onset of the bleeding, and after 2, 6, 12, 24, 48 , and 72 hours. No intervention was performed to CG while KT was applied to KTG after the onset of bleeding in the second menstrual phase.

Results: Headache and nausea at $2^{\text {nd }}$ hour; abdominal pain and dizziness at $6^{\text {th }}$ hour; abdominal pain, low back pain and fatigue at $12^{\text {th }}$ hour; abdominal pain, low back pain, thigh pain, nausea, dizziness and fatigue at $24^{\text {th }}$ hour; abdominal pain, low back pain and fatigue at $72^{\text {nd }}$ hour were significantly lower than the previous menstrual phase in KTG $(p<0.05)$. Dizziness at $6^{\text {th }}$ hour; thigh pain and fatigue at $12^{\text {th }}$ hour were significantly lower than the previous menstrual phase in CG $(\mathrm{p}<0.05)$.

Conclusion: Young women can benefit from Kinesio Tape application as an alternative, simple, reliable and effective method for reducing menstrual symptoms.

Keywords: Kinesio Tape, menstrual pain, menstrual symptoms, VAS 
enç kadınların \%75'inin menstrual siklus ile ilişkili çeşitli semptomlar yaşadığı bildirilmektedir. Bu semptomlar, kişinin günlük hayatı içerisindeki pek çok aktivitede kısıtlanmasına, akademik ve sosyal yaşamında ise sorunlara neden olabilmektedir $(1,2)$. Menstrüel şikayetlerin çok yaygın olması, bu durumun, maruz kalanlar tarafından normalleştirilmesine neden olduğundan prevelansı tam olarak belirlemek mümkün olamamaktadır. Ayrıca kültürel altyapı ve inanışlar da, kadınların menstruasyon belirtilerini saklamasının bir diğer nedeni olarak öne sürülmektedir $(3,4,5)$.

Menstrüel döngü içerisinde semptomlar, premenstrüel süreçte başlar ve karın ağrısı, baş ağrısı, mide bulantısı, şişlik ve hassasiyet gibi fiziksel semptomların yanında, anksiyete, depresyon gibi emosyonel sorunlara da neden olur. Premenstrüel semptomlar kanamanın başlamasıyla yerini menstrüel semptomlara bırakır (6). Menstrüasyon evresinde ağrı çoğunlukla alt karın bölgesinde görülürken, alt sırt ve/veya üst bacaklara da yayılabilir. Dismenore prevalansı için tahminler \%45 ila \%95 arasında değişmektedir. Yine menstrüasyon evresi ile ilişkili yaygın sistemik semptomlar arasında diyare, mide bulantısı, kusma, konsantrasyonda azalma, sırt ağrısı ve yorgunluk bildirilmektedir (1).

Araştırmalar, ağrının uterin prostaglandinlerden kaynaklandığını ve vazopressinin aşırı üretildiğini göstermektedir $(7,8)$. Medikal tedavi, menstrüasyonda prostaglandin üretimini etkileyerek ağrı ve semptomları hafifletir. Ancak bireyin ağrıya sistematik olarak maruz kalması, ağrının kontrolünde doğal ve yan etkisiz alternatif yöntemlerin üretilmesi ihtiyacını doğurmaktadır. Jinekologlar da, semptomların tedavisi için multidisipliner yaklaşımın tercih edilmesi gerektiğini kabul etmektedirler (3). Farmakolojik olmayan tedaviler ise genellikle, bitkisel ürünleri, diyet takviyelerini, beslenme değişikliklerini ve aktivite modifikasyonlarını içerir (7).

Kinezyo bantlama (KT), ince, pamuklu, akrilik yapışkanlı, lateks içermeyen, gözenekli terapatik bir banttır. Cildi kaldırarak, cilt ile kas arasındaki boşluğu artıırı, lokalize basıncı düşürür ve dolaşımı artırmaya, kas spazmını, ödemi ve ağrıyı azaltmaya yardımcı olur $(9,10,11)$. Literatürde, kinezyoteypin, premenstrüel ve menstrüel semptomlar üzerine etkilerinin araştırıldığı az sayıda çalışma mevcuttur. Ancak bu çalışmalar incelendiğinde menstrüasyon evresindeki ağrının lokalizasyonunun ve değişiminin ayrıntıI। bir şekilde değerlendirilmediği görülmektedir. Bugüne kadar yapılan çalışmalardan elde edilen sonuçlar, kinezyo bantlamanın menstrüasyon ağrısını azaltmaya katkı sağlayabileceği konusunda fikir vermekle birlikte, net bir sonuç ortaya koyamamaktadır.

Hipotezimiz kinezyo bantlama uygulamasının genç kadınlarda menstrüel semptomları azaltacağı yönündeydi. Bu hipotez doğrultusunda, çalışmamızın amacı genç kadınlarda kinezyo bantlama uygulamasının ağrı, bulantı, baş dönmesi ve yorgunluk semptomları üzerine etkisini araştırmaktır.

\section{Gereç ve yöntem}

Mevcut araştırma, randomize, tek kör, deneysel ön testson test çalışması şeklinde tasarlandı. Zonguldak Bülent Ecevit Üniversitesi Klinik Araştırmalar Etik Kurulu tarafından onaylanan (Protokol no: 2016-48-24/02) araştırmaya katılmaya gönüllü olan olgular, bilgilendirilmiş gönüllü olur formunu imzaladılar.

Bu çalışmaya Mart 2016 ile Temmuz 2016 tarihleri arasında, menstrüel semptomlardan şikayet eden 18-22 yaş arasında 28 kadın katılmıştır. Bekar olmak ve düzenli bir menstrüel döngüye sahip olmak (25-35 gün) çalışmanın dahil edilme kriteriydi. İntrauterin kontraseptif cihazı bulunan ve menstrüasyon evresinde oral kontraseptif ilaç kullananlar çalışmadan çıkarıldı. Uygun katılımcılar rastgele yöntemle kinezyo bantlama (KBG, $n=14$ ) ve kontrol grubu (KG, $n=14$ ) olmak üzere iki gruba ayrıldı.

Katılımcıların yaş (yıl), kilo $(\mathrm{kg})$ ve boy $(\mathrm{m})$ bilgileri kaydedildi. Menarşal yaş (yıl), menstrüel aralık (gün) ve menstrüasyon süresinden (gün) oluşan menstrüel hikayeleri alındı.

Semptomları değerlendirmek için ayrıntılı bir form (Şekil 1) hazırlandı. Bu formda, karın, bel ve uyluktaki ağrı yoğunluğu, baş ağrısı, bulantı, baş dönmesi ve yorgunluk semptomları 100 mm'lik Vizüel Analog Skala (VAS) ile değerlendirildi. Katılımcılara VAS açıklandıktan sonra, her katılımcıya 7 form verildi ve kanaması başladığında, başlangıçtan 2 saat, 6 saat, 12 saat, 24 saat, 48 saat ve 72 saat sonra bu formu işaretlemesi istendi.

Her katılımcı, çalışmaya katıldığı andan sonraki ilk menstrüasyon evresini ve ondan hemen sonraki menstrüasyon evresini kapsayacak şekilde toplamda iki kez değerlendirildi. Çalışma grubundaki katılımcılara, ikinci menstrüasyon evresinde, kanama başladıktan sonra, KB uygulaması yapıldı ve bu bandı 72 saat süresince çıkarmamaları istendi. KB uygulaması kinezyo bantlama sertifikası olan deneyimli bir fizyoterapist tarafından uygulanmıştır. Uygulama, 


\section{MENSTRÜEL SEMPTOMLAR İÇIN VIZÜEL ANALOG SKALA FORMU}

Lütfen değerlendirmeyi yaptığınız zamanı işaretleyin.
a) Kanama başladığında
b) Kanama başladıktan 2 saat sonra
c) Kanama başladıktan 6 saat sonra
d) Kanama başladıktan 12 saat sonra
e) Kanama başladıktan 24 saat sonra
f) Kanama başladıktan 48 saat sonra
g) Kanama başladıktan 72 saat sonra

Lütfen şikayetinizin şiddetine göre her bir cetvel üzerinde tek bir nokta işaretleyin

1. Karın Ağrısı

Yok. Dayanılmaz

2. Bel Ağrısı

Yok Dayanılmaz

3. Uyluk Ağrısı

Yok. Dayanılmaz

4. Baş Ağrısı

Yok. Dayanılmaz

5. Bulantı

Yok. Dayanılmaz

6. Baş Dönmesi

Yok. Dayanılmaz

7. Yorgunluk

Yok .Dayanılmaz 


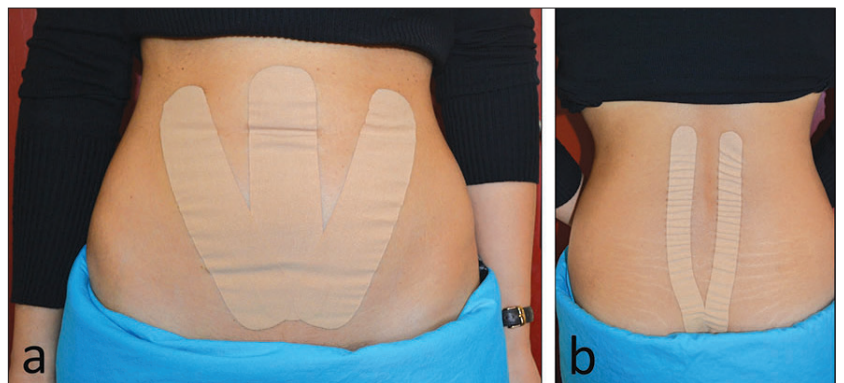

Şekil 2. KB uygulaması. A: Rektus abdominis ve eksternal oblik kaslara KB uygulaması; B: Erektör spinalara KB uygulaması

menstrüasyon sırasında sıklıkla spazma giren kasları etki edecek şekilde abdominal bölge ve alt sırt bölgesi üzerine uygulandı. Rectus abdominis, eksternal oblikler ve erector spinaları kapsayan uygulamada, hasta, ilgili kasının maksimum miktarda uzadığı pozisyona yerleştirildikten sonra ve bantta esneme oluşturmayacak şekilde kas liflerine paralel olarak uygulandı. Maksimum etki için istirahat pozisyonunda cilt katlantılarının oluşması beklendi (Şekil 2). KBG'deki katılımcıların ilk menstrüel evresinde ve kontrol grubunun her iki menstrüel evresinde herhangi bir müdahale yapılmadı.

\section{Istatistiksel analiz}

İstatistiksel analizler SPSS 15.0 paket programı ile yapıldı, p değeri 0,05 olarak alındı. Değişkenlerin normal dağılıma uygunluğu görsel (histogram ve olasılık grafikleri) ve analitik yöntemler (Kolmogorov-Smirnov/Shapiro-Wilk testleri) kullanılarak incelendi. Veriler normal dağılıma uygun olmadığı için KBG ve KG'nin başlangıç demografik verileri, menarş yaşı, menstrüel aralıkları ve menstrüasyon süreleri ile ikinci menstrüasyon evresine ait (KBG'ye KB uygulaması yapılmış olan evre) menstrüel semptomları Mann Whitney $\mathrm{U}$ testi kullanılarak karşılaştırıldı. KBG ve KG'nin birinci ve ikinci menstrüasyon evrelerine ait menstrüel semptomlarının grup içi karşılaştırmaları Wilcoxon testi ile yapıldı.

\section{Bulgular}

Yaş (yıl), boy (cm), kilo (kg) ve VKi (kg / m2) gibi demografik özellikler ve menstrüel aralık ve menstrüasyon süreleri açısından KBG ve KG arasında anlamlı fark yokken ( $p>0,05)$, menarş yaşı KBG'de, KG'ye göre daha düşüktü $(p<0,05)$ (Tablo 1).

KBG'de grup içi analiz sonuçları; kanama başladıktan 2 saat sonraki baş ağrısı ve bulantı semptomlarının, 6 saat sonraki karın ağrısı ve baş dönmesi semptomlarının, 12 saat sonraki karın ağrısı, bel ağrısı ve yorgunluk semptomlarının, 24 saat sonraki karın ağrısı, bel ağrısı, uyluk ağrısı,

\begin{tabular}{|c|c|c|c|}
\hline & $\begin{array}{c}K B G(n=14) \\
\pm S S\end{array}$ & $\begin{array}{c}K G(n=14) \\
\quad \pm S S\end{array}$ & $\begin{array}{c}p \\
\pm S S\end{array}$ \\
\hline Yaş (yıl) & $20,42 \pm 0,93$ & $21,07 \pm 1,14$ & 0,150 \\
\hline Boy (m) & $1,62 \pm 0,04$ & $1,65 \pm 0,05$ & 0,285 \\
\hline Kilo (kg) & $56,14 \pm 6,89$ & $57,07 \pm 8,80$ & 0,982 \\
\hline VKi (kg/m2) & $21,16 \pm 2,05$ & $20,87 \pm 3,26$ & 0,482 \\
\hline Menarş yaşı (yıl) & $13 \pm 0,78$ & $13,92 \pm 0,99$ & $0,019 *$ \\
\hline Menstrüel aralık (gün) & $28,57 \pm 1,08$ & $30,14 \pm 9,42$ & 0,541 \\
\hline Menstrüasyon süresi (gün) & $6,14 \pm 0,66$ & $5,85 \pm 1,83$ & 0,667 \\
\hline
\end{tabular}

bulantı, baş dönmesi ve yorgunluk semptomlarının ve 72 saat sonraki karın ağrısı, bel ağrısı ve yorgunluk semptomlarının şiddetinin bir önceki menstrüasyon evresine göre anlamlı olarak azaldığını $(p<0,05)$ ortaya koydu. KBG'de kalan parametreler açısından iki menstrüel evre arasında anlamlı fark bulunmadı ( $p>0,05$ ) (Tablo 2 ).

KG'de grup içi analiz sonuçları; kanama başladıktan 6 saat sonraki baş dönmesi semptomunun ve 12 saat sonraki uyluk ağrısı ve yorgunluk şiddetinin bir önceki menstrüasyon evresine göre anlamlı olarak azaldığını $(p<0,05)$ ortaya koydu. KG'de kalan parametreler açısından iki menstrüel evre arasında anlamlı fark bulunmadı ( $p>0,05)$ (Tablo 3 ).

KBG ve KG'nin gruplar arası analiz sonuçları ise; kanama başladığı sıradaki karın ağrısı, uyluk ağrısı ve bulantı, 2 saat sonraki baş ağrısı, bulantı ve baş dönmesi, 6 saat sonraki baş ağrısı, bulantı ve baş dönmesi, 12 saat sonraki baş ağrısı, bulantı ve baş dönmesi, 24 saat sonraki uyluk ağrıSı, baş ağrısı, bulantı, baş dönmesi ve yorgunluk, 48 saat sonraki baş ağrısı, bulantı ve baş dönmesi, 72 saat sonraki karın ağrısı, bel ağrısı, uyluk ağrısı, baş ağrısı, bulantı, baş dönmesi ve yorgunluk şiddetinin KBG'de KG'ye göre anlamlı olarak daha az $(p<0,05)$ olduğunu gösterdi. Kalan parametreler açısından iki grup arasında anlamlı fark bulunmadı $(p>0,05)$ (Tablo 4).

\section{Tartışma}

Genç kadınlarda sıklıkla karşılaşılan menstrüel semptomlardan karın, bel ve uyluk ağrısının yanısıra, baş ağrısı, baş dönmesi, bulantı ve yorgunluk şiddetlerinin de kanama başladığı andan üçüncü güne değin, çeşitli zamanlarda değerlendirildiği bu çalışmada, kinezyo bantlama uygulamasının, menstrüasyon semptomlarını azaltmada yüksek oranda etkili olduğu görülmüştür. 
Tablo 2. KBG'nin menstrüel semptomlarııın grup içi karşılaştııılması

\begin{tabular}{|c|c|c|c|c|c|c|c|c|c|c|c|c|c|c|c|c|c|c|c|c|c|}
\hline & \multicolumn{3}{|c|}{$\begin{array}{c}\text { Kanama } \\
\text { baş/adığında VAS } \\
(n=14)\end{array}$} & \multicolumn{3}{|c|}{$\begin{array}{c}2 \text { saat sonra VAS } \\
(n=14)\end{array}$} & \multicolumn{3}{|c|}{$\begin{array}{c}6 \text { saat sonra VAS } \\
(n=14)\end{array}$} & \multicolumn{3}{|c|}{$\begin{array}{c}12 \text { saat sonra VAS } \\
(n=14)\end{array}$} & \multicolumn{3}{|c|}{$\begin{array}{c}24 \text { saat sonra VAS } \\
\qquad(n=14)\end{array}$} & \multicolumn{3}{|c|}{$\begin{array}{c}48 \text { saat sonra VAS } \\
\qquad(n=14)\end{array}$} & \multicolumn{3}{|c|}{$\begin{array}{c}72 \text { saat sonra VAS } \\
(n=14)\end{array}$} \\
\hline & $\begin{array}{c}i \\
\bar{x} \pm S S\end{array}$ & $\begin{array}{c}S \\
\bar{x} \pm S S\end{array}$ & $p$ & $\begin{array}{c}i \\
\bar{x} \pm S S\end{array}$ & $\begin{array}{c}S \\
\bar{x} \pm S S\end{array}$ & $p$ & $\begin{array}{c}i \\
\bar{x} \pm S S\end{array}$ & $\begin{array}{c}S \\
\bar{x} \pm S S\end{array}$ & $p$ & $\begin{array}{c}i \\
\bar{x} \pm S S\end{array}$ & $\begin{array}{c}S \\
\bar{x} \pm S S\end{array}$ & $p$ & $\begin{array}{c}i \\
\bar{x} \pm S S\end{array}$ & $\begin{array}{c}S \\
\bar{x} \pm S S\end{array}$ & $p$ & $\begin{array}{c}i \\
\bar{x} \pm S S\end{array}$ & $\begin{array}{c}S \\
\bar{x} \pm S S\end{array}$ & $p$ & $\begin{array}{c}i \\
\bar{x} \pm S S\end{array}$ & $\begin{array}{c}S \\
\bar{x} \pm S S\end{array}$ & $p$ \\
\hline $\begin{array}{l}\text { Karın ağrısı } \\
\text { (cm) }\end{array}$ & $2,57 \pm 2,90$ & $2,42 \pm 3,11$ & 0,916 & $3,85 \pm 3,25$ & $2,85 \pm 3,31$ & 0,199 & $5,42 \pm 2,83$ & $3,00 \pm 2,93$ & $0,047^{*}$ & $5,42 \pm 2,06$ & $3,28 \pm 3,44$ & $0,036^{*}$ & $3,78 \pm 2,89$ & $2,21 \pm 2,38$ & $0,001^{*}$ & $1,35 \pm 2,65$ & $0,92 \pm 1,12$ & 0,776 & $1,24 \pm 1,90$ & $0,28 \pm 0,72$ & $0,026^{*}$ \\
\hline $\begin{array}{l}\text { Bel ağrısı } \\
\text { (cm) }\end{array}$ & $3,38 \pm 2,79$ & $2,71 \pm 3,36$ & 0,430 & $3,50 \pm 2,44$ & $3,57 \pm 3,35$ & 0,975 & $4,35 \pm 3,09$ & $3,85 \pm 2,97$ & 0,331 & $5,50 \pm 3,36$ & $3,28 \pm 3,16$ & $0,002^{*}$ & $5,28 \pm 3,36$ & $1,71 \pm 2,46$ & $0,005^{*}$ & $1,71 \pm 2,95$ & $0,74 \pm 0,91$ & 0,325 & $1,24 \pm 2,13$ & $0,14 \pm 0,36$ & $0,026^{*}$ \\
\hline $\begin{array}{l}\text { Uyluk ağrısı } \\
\text { (cm) }\end{array}$ & $1,07 \pm 1,05$ & $1,57 \pm 2,27$ & 0,384 & $1,28 \pm 1,46$ & $2,50 \pm 2,93$ & 0,065 & $1,78 \pm 1,56$ & $1,85 \pm 2,26$ & 0,673 & $2,04 \pm 2,14$ & $1,28 \pm 1,91$ & 0,199 & $3,35 \pm 2,72$ & $0,64 \pm 1,43$ & $0,002^{*}$ & $0,78 \pm 1,79$ & $0,64 \pm 1,26$ & 0,459 & $0,78 \pm 1,61$ & $0,28 \pm 0,72$ & 0,458 \\
\hline $\begin{array}{l}\text { Baş ağrısı } \\
(\mathrm{cm})\end{array}$ & $0,71 \pm 0,91$ & $0,78 \pm 0,87$ & 0,670 & $0,78 \pm 1,10$ & $0,07 \pm 0,18$ & $0,023^{*}$ & $1,00 \pm 1,98$ & $0,07 \pm 0,18$ & 0,063 & $0,35 \pm 0,90$ & $0,07 \pm 0,18$ & 0,458 & $0,17 \pm 0,28$ & $0,50 \pm 1,27$ & 0,916 & $0,14 \pm 0,36$ & $0,35 \pm 0,90$ & 0,458 & $0,28 \pm 0,72$ & $0,42 \pm 1,08$ & 0,458 \\
\hline Bulantı (cm) & $0,50 \pm 1,07$ & $0,28 \pm 0,37$ & 0,914 & $1,28 \pm 1,95$ & $0,07 \pm 0,18$ & $0,023^{*}$ & $2,14 \pm 2,85$ & $0,78 \pm 1,79$ & 0,199 & $1,07 \pm 1,60$ & $0,07 \pm 0,18$ & 0,062 & $0,57 \pm 1,05$ & $0,00 \pm 0,00$ & $0,023^{*}$ & $0,14 \pm 0,36$ & $0,00 \pm 0,00$ & 0,157 & $0,14 \pm 0,36$ & $0,00 \pm 0,00$ & 0,157 \\
\hline $\begin{array}{l}\text { Baş dönmesi } \\
\text { (cm) }\end{array}$ & $1,50 \pm 3,22$ & $0,50 \pm 0,73$ & 0,914 & $0,78 \pm 1,61$ & $0,21 \pm 0,54$ & 0,063 & $0,85 \pm 1,58$ & $0,07 \pm 0,18$ & $0,026^{*}$ & $0,35 \pm 0,71$ & $0,07 \pm 0,18$ & 0,063 & $0,28 \pm 0,37$ & $0,00 \pm 0,00$ & $0,023^{*}$ & $0,00 \pm 0,00$ & $0,00 \pm 0,00$ & 1,000 & $0,00 \pm 0,00$ & $0,00 \pm 0,00$ & 1,000 \\
\hline $\begin{array}{l}\text { Yorgunluk } \\
\text { (cm) }\end{array}$ & $3,50 \pm 2,77$ & $2,92 \pm 2,86$ & 0,592 & $4,07 \pm 2,83$ & $3,57 \pm 3,41$ & 0,386 & $4,85 \pm 2,67$ & $3,78 \pm 2,90$ & 0,120 & $5,02 \pm 3,01$ & $2,32 \pm 2,65$ & $0,002^{*}$ & $4,00 \pm 3,03$ & $1,92 \pm 2,48$ & $0,002^{*}$ & $1,50 \pm 2,84$ & $1,28 \pm 1,99$ & 0,673 & $2,07 \pm 2,91$ & $0,57 \pm 1,08$ & $0,033^{*}$ \\
\hline
\end{tabular}

Tablo 3. KG'nin menstrüel semptomlarının grup içi karşılaştırılması

\begin{tabular}{|c|c|c|c|c|c|c|c|c|c|c|c|c|c|c|c|c|c|c|c|c|c|}
\hline & \multicolumn{3}{|c|}{$\begin{array}{c}\text { Kanama başladığında VAS } \\
(n=14)\end{array}$} & \multicolumn{3}{|c|}{$\begin{array}{c}2 \text { saat sonra VAS } \\
\quad(n=14)\end{array}$} & \multicolumn{3}{|c|}{$\begin{array}{c}6 \text { saat sonra VAS } \\
(n=14)\end{array}$} & \multicolumn{3}{|c|}{$\begin{array}{c}12 \text { saat sonra VAS } \\
(n=14)\end{array}$} & \multicolumn{3}{|c|}{$\begin{array}{c}24 \text { saat sonra VAS } \\
(n=14)\end{array}$} & \multicolumn{3}{|c|}{$\begin{array}{l}48 \text { saat sonra VAS } \\
\qquad(n=14)\end{array}$} & \multicolumn{3}{|c|}{$\begin{array}{c}72 \text { saat sonra VAS } \\
(n=14)\end{array}$} \\
\hline & $\begin{array}{c}i \\
\bar{x} \pm S S\end{array}$ & $\begin{array}{c}S \\
\bar{x} \pm S S\end{array}$ & $p$ & $\begin{array}{c}i \\
\bar{x} \pm S S\end{array}$ & $\begin{array}{c}S \\
\bar{x} \pm S S\end{array}$ & $p$ & $\begin{array}{c}i \\
\bar{x} \pm S S\end{array}$ & $\underset{\bar{x} \pm S S}{S}$ & $p$ & $\begin{array}{c}i \\
\bar{x} \pm S S\end{array}$ & $\begin{array}{c}S \\
\bar{x} \pm S S\end{array}$ & $p$ & $\begin{array}{c}i \\
\bar{x} \pm S S\end{array}$ & $\underset{\bar{x} \pm S S}{S}$ & $p$ & $\begin{array}{c}i \\
\bar{x} \pm S S\end{array}$ & $\begin{array}{c}S \\
\bar{x} \pm S S\end{array}$ & $p$ & $\begin{array}{c}i \\
\bar{x} \pm S S\end{array}$ & $\begin{array}{c}S \\
\bar{x} \pm S S\end{array}$ & $p$ \\
\hline $\begin{array}{l}\text { Karın ağrısı } \\
\text { (cm) }\end{array}$ & $5,75 \pm 2,99$ & $5,30 \pm 2,71$ & 0,056 & $5,07 \pm 2,95$ & $5,00 \pm 2,94$ & 0,516 & $5,39 \pm 2,77$ & $4,85 \pm 2,79$ & 0,103 & $4,96 \pm 2,83$ & $4,67 \pm 2,99$ & 0,366 & $4,14 \pm 3,04$ & $4,46 \pm 3,31$ & 0,109 & $2,82 \pm 2,74$ & $2,46 \pm 2,47$ & 0,223 & $1,87 \pm 2,34$ & $1,16 \pm 1,35$ & 0,144 \\
\hline $\begin{array}{l}\text { Bel ağrısı } \\
(\mathrm{cm})\end{array}$ & $4,32 \pm 3,67$ & $4,46 \pm 3,63$ & 0,157 & $3,78 \pm 3,36$ & $3,53 \pm 3,02$ & 0,336 & $4,35 \pm 3,44$ & $4,10 \pm 3,40$ & 0,161 & $4,03 \pm 3,24$ & $4,10 \pm 3,13$ & 0,680 & $3,85 \pm 3,05$ & $3,96 \pm 3,17$ & 0,581 & $2,69 \pm 2,69$ & $2,51 \pm 2,46$ & 0,588 & $1,71 \pm 2,31$ & $1,14 \pm 1,43$ & 0,197 \\
\hline $\begin{array}{l}\text { Uyluk ağrısı } \\
\text { (cm) }\end{array}$ & $3,17 \pm 3,19$ & $3,21 \pm 3,19$ & 0,888 & $2,71 \pm 2,77$ & $2,35 \pm 2,58$ & 0,109 & $2,84 \pm 3,09$ & $2,62 \pm 2,56$ & 0,306 & $2,64 \pm 2,90$ & $2,17 \pm 2,46$ & $0,041^{*}$ & $3,03 \pm 2,99$ & $2,92 \pm 2,98$ & 0,470 & $2,26 \pm 2,54$ & $1,80 \pm 2,14$ & 0,351 & $1,51 \pm 1,92$ & $0,94 \pm 0,78$ & 0,157 \\
\hline $\begin{array}{l}\text { Başağrısı } \\
\text { (cm) }\end{array}$ & $2,64 \pm 2,76$ & $2,78 \pm 2,74$ & 0,336 & $3,02 \pm 3,51$ & $3,02 \pm 3,26$ & 1,000 & $2,12 \pm 2,63$ & $2,32 \pm 2,53$ & 0,590 & $2,14 \pm 2,49$ & $2,14 \pm 2,23$ & 0,829 & $2,10 \pm 2,55$ & $2,17 \pm 2,62$ & 0,655 & $2,02 \pm 2,74$ & $1,41 \pm 2,20$ & 0,416 & $1,55 \pm 1,90$ & $1,07 \pm 1,56$ & 0,344 \\
\hline Bulantı (cm) & $2,67 \pm 2,39$ & $2,53 \pm 2,17$ & 0,414 & $2,57 \pm 2,68$ & $2,14 \pm 2,08$ & 0,168 & $2,78 \pm 2,68$ & $2,39 \pm 1,98$ & 0,750 & $2,57 \pm 2,57$ & $1,92 \pm 1,87$ & 0,066 & $2,10 \pm 2,54$ & $1,82 \pm 2,22$ & 0,439 & $1,67 \pm 2,12$ & $1,25 \pm 1,72$ & 0,102 & $1,53 \pm 2,06$ & $0,71 \pm 0,87$ & 0,141 \\
\hline $\begin{array}{l}\text { Baş dönmesi } \\
\text { (cm) }\end{array}$ & $2,26 \pm 2,71$ & $1,85 \pm 2,24$ & 0,225 & $2,03 \pm 2,59$ & $1,60 \pm 2,04$ & 0,102 & $2,03 \pm 2,41$ & $1,39 \pm 1,78$ & $0,042^{*}$ & $2,35 \pm 2,53$ & $2,10 \pm 1,74$ & 0,733 & $1,78 \pm 2,26$ & $1,50 \pm 2,00$ & 0,443 & $1,46 \pm 1,80$ & $1,03 \pm 1,26$ & 0,102 & $1,10 \pm 1,67$ & $0,60 \pm 0,62$ & 0,285 \\
\hline $\begin{array}{l}\text { Yorgunluk } \\
(\mathrm{cm})\end{array}$ & $4,65 \pm 3,21$ & $4,39 \pm 2,96$ & 0,611 & $3,17 \pm 2,35$ & $3,03 \pm 2,30$ & 0,832 & $4,37 \pm 2,63$ & $4,32 \pm 2,53$ & 0,854 & $4,00 \pm 2,57$ & $3,28 \pm 2,22$ & $0,040^{*}$ & $4,75 \pm 3,17$ & $4,32 \pm 3,23$ & 0,400 & $2,39 \pm 2,25$ & $2,32 \pm 2,08$ & 1,000 & $1,95 \pm 2,02$ & $1,65 \pm 1,45$ & 0,674 \\
\hline
\end{tabular}

Tablo 4. KG ve KBG'nin menstrüel semptomlarının gruplar arası karşılaştırıması

\begin{tabular}{|c|c|c|c|c|c|c|c|c|c|c|c|c|c|c|c|c|c|c|c|c|c|}
\hline & \multicolumn{3}{|c|}{$\begin{array}{c}\text { Kanama başladığıında VAS } \\
(n=14)\end{array}$} & \multicolumn{3}{|c|}{$\begin{array}{c}2 \text { saat sonra VAS } \\
(n=14)\end{array}$} & \multicolumn{3}{|c|}{$\begin{array}{c}6 \text { saat sonra VAS } \\
(n=14)\end{array}$} & \multicolumn{3}{|c|}{$\begin{array}{c}12 \text { saat sonra VAS } \\
(n=14)\end{array}$} & \multicolumn{3}{|c|}{$\begin{array}{c}24 \text { saat sonra VAS } \\
(n=14)\end{array}$} & \multicolumn{3}{|c|}{$\begin{array}{c}48 \text { saat sonra VAS } \\
(n=14)\end{array}$} & \multicolumn{3}{|c|}{$\begin{array}{c}72 \text { saat sonra VAS } \\
(n=14)\end{array}$} \\
\hline & $\begin{array}{c}K G \\
\bar{x} \pm S S\end{array}$ & $\begin{array}{c}K B G \\
\bar{x} \pm S S\end{array}$ & $p$ & $\begin{array}{c}K G \\
\bar{x} \pm S S\end{array}$ & $\begin{array}{c}K B G \\
\bar{x} \pm S S\end{array}$ & $p$ & $\begin{array}{c}K G \\
\bar{x} \pm S S\end{array}$ & $\begin{array}{c}K B G \\
\bar{x} \pm S S\end{array}$ & $p$ & $\begin{array}{c}K G \\
\bar{x} \pm S S\end{array}$ & $\begin{array}{c}K B G \\
\bar{x} \pm S S\end{array}$ & $p$ & $\begin{array}{c}K G \\
\bar{x} \pm S S\end{array}$ & $\begin{array}{c}K B G \\
\bar{x} \pm S S\end{array}$ & $p$ & $\begin{array}{c}K G \\
\bar{x} \pm S S\end{array}$ & $\begin{array}{c}K B G \\
\bar{x} \pm S S\end{array}$ & $p$ & $\begin{array}{c}K G \\
\bar{x} \pm S S\end{array}$ & $\begin{array}{c}K B G \\
\bar{x} \pm S S\end{array}$ & $p$ \\
\hline $\begin{array}{l}\text { Karın ağrısı } \\
\text { (cm) }\end{array}$ & $5,30 \pm 2,71$ & $2,42 \pm 3,11$ & $0,050^{*}$ & $5,00 \pm 2,94$ & $2,85 \pm 3,31$ & 0,094 & $4,85 \pm 2,79$ & $3,00 \pm 2,93$ & 0,094 & $4,67 \pm 2,99$ & $3,28 \pm 3,44$ & 0,246 & $4,46 \pm 3,31$ & $2,21 \pm 2,38$ & 0,056 & $2,46 \pm 2,47$ & $0,92 \pm 1,12$ & 0,125 & $1,16 \pm 1,35$ & $0,28 \pm 0,72$ & $0,014^{*}$ \\
\hline $\begin{array}{l}\text { Bel ağrısı } \\
\text { (cm) }\end{array}$ & $4,46 \pm 3,63$ & $2,71 \pm 3,36$ & 0,329 & $3,53 \pm 3,02$ & $3,57 \pm 3,35$ & 0,839 & $4,10 \pm 3,40$ & $3,85 \pm 2,97$ & 0,734 & $4,10 \pm 3,13$ & $3,28 \pm 3,16$ & 0,401 & $3,96 \pm 3,17$ & $1,71 \pm 2,46$ & 0,056 & $2,51 \pm 2,46$ & $0,74 \pm 0,91$ & 0,056 & $1,14 \pm 1,43$ & $0,14 \pm 0,36$ & $0,009^{*}$ \\
\hline $\begin{array}{l}\text { Uyluk ağrısı } \\
\text { (cm) }\end{array}$ & $3,21 \pm 3,19$ & $1,57 \pm 2,27$ & $0,050^{*}$ & $2,35 \pm 2,58$ & $2,50 \pm 2,93$ & 0,769 & $2,62 \pm 2,56$ & $1,85 \pm 2,26$ & 0,571 & $2,17 \pm 2,46$ & $1,28 \pm 1,91$ & 0,265 & $2,92 \pm 2,98$ & $0,64 \pm 1,43$ & $0,009^{*}$ & $1,80 \pm 2,14$ & $0,64 \pm 1,26$ & 0,085 & $0,94 \pm 0,78$ & $0,28 \pm 0,72$ & $0,009 *$ \\
\hline $\begin{array}{l}\text { Başağ rısı } \\
\text { (cm) }\end{array}$ & $2,78 \pm 2,74$ & $0,78 \pm 0,87$ & 0,104 & $3,02 \pm 3,26$ & $0,07 \pm 0,18$ & $0,001^{*}$ & $2,32 \pm 2,53$ & $0,07 \pm 0,18$ & $0,001^{*}$ & $2,14 \pm 2,23$ & $0,07 \pm 0,18$ & $0,000^{*}$ & $2,17 \pm 2,62$ & $0,50 \pm 1,27$ & $0,021^{*}$ & $1,41 \pm 2,20$ & $0,35 \pm 0,90$ & $0,035^{*}$ & $1,07 \pm 1,56$ & $0,42 \pm 1,08$ & $0,027^{*}$ \\
\hline $\begin{array}{l}\text { Bulantı } \\
\text { (cm) }\end{array}$ & $2,53 \pm 2,17$ & $0,28 \pm 0,37$ & $0,004^{*}$ & $2,14 \pm 2,08$ & $0,07 \pm 0,18$ & $0,000^{*}$ & $2,39 \pm 1,98$ & $0,78 \pm 1,79$ & $0,006^{*}$ & $1,92 \pm 1,87$ & $0,07 \pm 0,18$ & $0,000^{*}$ & $1,82 \pm 2,22$ & $0,00 \pm 0,00$ & $0,003^{*}$ & $1,25 \pm 1,72$ & $0,00 \pm 0,00$ & $0,003^{*}$ & $0,71 \pm 0,87$ & $0,00 \pm 0,00$ & $0,003^{*}$ \\
\hline $\begin{array}{l}\text { Baş } \\
\text { dönmesi } \\
\text { (cm) }\end{array}$ & $1,85 \pm 2,24$ & $0,50 \pm 0,73$ & 0,125 & $1,60 \pm 2,04$ & $0,21 \pm 0,54$ & $0,012^{*}$ & $1,39 \pm 1,78$ & $0,07 \pm 0,18$ & $0,002^{*}$ & $2,10 \pm 1,74$ & $0,07 \pm 0,18$ & $0,000^{*}$ & $1,50 \pm 2,00$ & $0,00 \pm 0,00$ & $0,001^{*}$ & $1,03 \pm 1,26$ & $0,00 \pm 0,00$ & $0,003^{*}$ & $0,60 \pm 0,62$ & $0,00 \pm 0,00$ & $0,003^{*}$ \\
\hline $\begin{array}{l}\text { Yorgunluk } \\
\text { (cm) }\end{array}$ & $4,39 \pm 2,96$ & $2,92 \pm 2,86$ & 0,178 & $3,03 \pm 2,30$ & $3,57 \pm 3,41$ & 0,804 & $4,32 \pm 2,53$ & $3,78 \pm 2,90$ & 0,667 & $3,28 \pm 2,22$ & $2,32 \pm 2,65$ & 0,164 & $4,32 \pm 3,23$ & $1,92 \pm 2,48$ & $0,035^{*}$ & $2,32 \pm 2,08$ & $1,28 \pm 1,99$ & 0,164 & $1,65 \pm 1,45$ & $0,57 \pm 1,08$ & $0,027^{*}$ \\
\hline
\end{tabular}


Kanamanın başlangıcından itibaren ilk üç gün boyunca ağrı, menstrüel semptomların en sık görülen belirtisidir ve yoğunlukla pelvik bölge, bel çevresi ve uyluk bölgelerinde hissedilir. Menstrüasyon sırasında prostaglandinin aşırı artışına bağlı gelişen uterus kontraksiyonu ve uterin arteriollerinin vazospazmının, karın çevresinde ağrıyla sonuçlanan iskemi ve kramplara neden olduğu düşünülmektedir (12). Premenstrüel ve menstrüel semptomlarla başetmek için pek çok alternatif yöntem denenmiştir. Bu yöntemlerden biri olan bantlama ile yapılan çalışmaların pek çoğunda bantlamanın menstrüel ağrıyı azaltmaya katkı sağlayabileceği bildirilmektedir (13-19).

Ancak literatürde, diğer bantlardan farklı olarak oldukça esnek bir bant olan ve vücuda özel bir teknikle uygulanan KB'nin menstrüel ağrı üzerine etkinliğini araştıran çalışmaların sayısı çok azdır (14-17). KB ve spiral bantlamanın menstrüel ve premenstrüel semptomlar üzerindeki etkisinin araştırıldığı bir çalışmada her iki bantın da menstrüel ağrıyı azaltmada etkili olduğu görülürken, KB'nin premenstrüel semptomlar üzerinde etkili olmadığı bildirilmiştir (14). Bir başka çalışmada ise KB uygulamasının hem premenstrüel hem de menstrüel semptomları azaltmada etkili olduğu gösterilmiştir (15). Ancak bu çalışmalarda ağrı değerlendirmesinin lokalizasyonu veya zamanı hakkında ayrıntılı bilgiye rastlanmamaktadır. Ağrı algısını etkileyen pek çok intrinsik ve ekstrinsik faktörün olduğu dikkate alındığında üç güne kadar sürebilen ağrılı bir sürecin hangi aşamasında değerlendirme yapıldığını bilmek, ağrının değişimini netlikle ortaya koyabilmek için önem arz etmektedir. Bu nedenle, menstrüel dönem boyunca tek bir değerlendirmeyle ağrıyı objektif olarak değerlendirmek gerçekçi bir yaklaşım değildir. Ayrıca, daha önce yapılan çalışmalarda ve bizim çalışmamızda uygulanan bantlama tekniğinin ve bantlamanın yapıldığı sürecin birbirinden farklı olduğu görülmektedir. Bu nedenle, çalışmamızın daha önceki çalışmalar ile tutarlıığı hakkında net bir yorum yapmak mümkün olamamaktadır.

Bu çalışma, KBG'ye kanama başladıktan sonra uygulanan KB'nin karın, bel ve uyluk ağrısı üzerine 6. saat itibariyle etki göstermeye başladığını, 24. saatte bu etkinin maksimuma ulaştığını ve 72 . saate kadar azalarak devam ettiğini göstermektedir. KB'nin ağrıyı azaltmadaki etkinlik mekanizması üzerine geliştirilen hipotezler arasında; uygulandığı bölgedeki kutanöz afferentleri uyararak kas tonusunu regüle etmesi, resiprokal inervasyon yoluyla iç organlara etki etmesi ve spinal kordda prostaglandinin ağrıyı hassaslaştırıcı etkisini bastıran taktil fibrilleri uyararak, presinaptik inhibisyon sağlaması yer almaktadır (14).
Bizim çalışmamızın sonuçları da bu hipotezleri destekler niteliktedir.

Çalışmamız menstrüel evrede sıklıkla görülen diğer semptomlar üzerinde de KB uygulamasının etkili olduğu göstermiştir. KB'nin ağrıyı azaltmadaki etki mekanizmasına yönelik hipotezlerin baş ağrısı, bulantı, baş dönmesi ve yorgunluk şiddetini azaltmada primer etki göstermesi beklenemez. Ancak KB uygulamasının bu semptomlar üzerindeki maksimum etkisinin de 24. saatte oluşması, yani bu etkinin ağrı semptomuna yönelik etkiyle paralellik göstermesi, durumun rastlantısal olmadığını düşündürmektedir. Menstrual siklus içerisinde premenstrüel ve menstrüel dönemde değişen hormonal salınım ve ağrıya bağlı artan agresyonun diğer semptomların oluşmasında etken olduğu bilinen bir gerçektir $(20,21)$. Bu çalışma kapsamında yer almamakla birlikte, ağrının azalmasına paralel olarak, anksiyetenin azalmış olması ve bunun da diğer semptomların oluşmasını ve/veya algılanmasını azaltması muhtemel bir etki mekanizması olarak düşünülebilir. Yine kas spazmının azalmasına bağlı olarak artan parasempatik aktivitenin de baş ağrısı, baş dönmesi, bulantı ve yorgunluk şikayetlerini azaltmada etkili olabileceği düşüncesindeyiz.

Çalışmamızın sonuçlarına göre, herhangi bir uygulama yapılmayan KG'de de kanama başladıktan 6 saat sonraki baş dönmesi semptomunun ve 12 saat sonraki uyluk ağrısı ve yorgunluk şiddetinin bir önceki menstrüasyon evresine göre anlamlı olarak azaldığı görülmüştür. Bu noktada düşüncemiz, bu değişimin mevsimsel değişiklikler ve/veya kişisel nedenler gibi kontrol edemediğimiz diğer faktörler sonucu gelişebileceği yönündedir.

Bu çalışmaya katılan olgu sayısının görece az olması çalışmanın sonuçlarının güvenilirliğini sınırlamaktadır. Ayrıca olguların semptom yoğunluklarının standardize edilmemiş olması bu çalışmanın diğer bir limitasyonudur.

Menstrüel semptomların premenopozal dönemdeki kadınların günlük yaşam aktivitelerini ve yaşam kalitesini olumsuz yönde etkilediği bilinmektedir. Pek çok kadın bu semptomlarla başa çıkmak için farmakolojik tedaviye başvurmakta ancak bunun devamlılık arz eden bir durum olması itibariyle de yan etkisi olmayan alternatif ve güvenli yöntemler aramaktadır. Bu çalışma, kadınların menstrüel semptomlarını azaltmaya yönelik basit, güvenilir ve etkili alternatif bir yöntem olarak kinezyo bantlama uygulamasından yararlanabileceğini göstermektedir. 


\section{Kaynaklar}

1. Daley AJ. Exercise and primary dysmenorrhoea. Sports Med 2008; 38: 659-70. [CrossRef]

2. Sommer B. How does menstruation affect cognitive competence and psychophysiological response?. Women Health 1983; 8: 53-90. [CrossRef]

3. Berkley KJ, McAllister SL. Don't dismiss dysmenorrhea!. Pain 2011; 152: 1940-1. [CrossRef]

4. McKeever P. "The perpetuation of menstrual shame: Implications and directions." Women Health 1984; 9: 33-47. [CrossRef]

5. Rothbaum $\mathrm{BO}$, Jackson J. Religious influence on menstrual attitudes and symptoms. Women Health 1990; 16: 63-78. [CrossRef]

6. Vani KR, KSV, LS, Kumar VRH, AB. Menstrual Abnormalities in School Going Girls-Are They Related to Dietary and Exercise Pattern?. J Clin Diagn Res 2013; 7: 2537-40 [CrossRef]

7. Onur O, Gumus I, Derbent A, Kaygusuz I, Simavli S, Urun E, et al. Impact of home-based exercise on quality of life of women with primary dysmenorrhoea. S Afr J Obstet Gynaecol 2012 18: 15-8.

8. Hightower M. Effects of exercise participation on menstrual pain and symptoms. Women Health 1997; 26: 15-27.

9. Akinbo SR, Ojetunde AM. Comparison of the Effect of Kinesiotape on Pain and Joint Range of Motion in Patients with Knee Joint Osteoarthritis and Knee Sport Injury. Niger Med Pract 2007; 52: 65-9. [CrossRef]

10. Fu TC, Wong AM, Pei YC, Wu KP, Chou SW, Lin YC. Effect of Kinesio taping on muscle strength in athletes-a pilot study. J Sci Med Sport 2008; 11: 198-201. [CrossRef]

11. Akbas E, Atay AO, Yuksel I. The effects of additional kinesio taping over exercise in the treatment of patellofemoral pain syndrome. Acta Orthop Traumatol Turc 2011; 45: 335-41. [CrossRef]

12. Munawar, Nurjannah, Nurviana F. 2013. The Effect of aerobics on reducing the pain of dysmenorrhea. Paper read at Proceedings of The Annual International Conference, Syiah Kuala University-Life Sciences \& Engineering Chapter 2013; 3: 244-7.
13. Lismidiati W, Santi NF, Akbar HW. Pengaruh Self Tapping terhadap Penurunan Level Dysmenorhea pada Mahasiswi Program Studi IImu Keperawatan. Jurnal Keperawatan Padjadjaran 2017; 5: 57-64. [CrossRef]

14. Lim C, Park Y, Bae Y. The effect of the kinesio taping and spiral taping on menstrual pain and premenstrual syndrome. J Phys Ther Sci 2013; 25:761-4. [CrossRef]

15. Do ES, Park KM, Lee SH. A study on the effects of the kinesio tape method on perimenstrual discomforts. J Korean Community Nurs 2003;14: 415-23.

16. Forozeshfard $M$, Bakhtiary $A H$, Aminianfar $A$, Sheikhian $S$, Akbarzadeh Z. Short term effects of kinesio taping on pain and functional disability in young females with menstrual low back pain: A randomised control trial study. J Back Musculoskelet Rehabil 2016;29:709-15. [CrossRef]

17. Kaur A, Ray G, Mitra M. Comparing the Effectiveness of Connective Tissue Mobilisation and Kinesio-taping on Females with Primary Dysmenorrhea. Indian Journal of Physiotherapy \& Occupational Therapy, 2017; 11: 70-5. [CrossRef]

18. Yum KS, Kang SG, Han HJ. The effect of balance taping for prevention of menstrual pain in female middle school students. J Phys Ther Sci 2017; 29: 813-8. [CrossRef]

19. Tomás-Rodrígue MI, Palazón-Bru A, John DRJMS, ToledoMarhuenda JV, Asensio-García MDR, Gil-Guillén VF. Effectiveness of medical taping concept in primary dysmenorrhoea: a two-armed randomized trial. Sci Rep 2015; 5: 1-5. [CrossRef]

20. Alonso C, Coe CL. Disruptions of social relationships accentuate the association between emotional distress and menstrual pain in young women. Health Psychol 2001; 20: 411-6.

21. Tu CH, Niddam DM, Chao HT, Chen LF, Chen YS, Wu YT, et al. Brain morphological changes associated with cyclic menstrual pain. Pain 2010; 150: 462-8. [CrossRef] 